\title{
THE ANNUAL MEETING OF THE SOCIETY
}

The forty-sixth Annual Meeting of the American Mathematical Society was held at the Ohio State University, Columbus, Ohio, from Tuesday to Friday, December 26-29, 1939, in conjunction with the meetings of the American Association for the Advancement of Science, the Mathematical Association of America, and the National Council of Teachers of Mathematics. This was the fifth time the Society has met at the Ohio State University, the other meetings being in the years 1899, 1915, 1926, and 1931.

There were four general and nine sectional sessions of the Society, at which eight addresses and one hundred two research papers (sixtytwo in person) were given. The Gibbs Lecture on Wednesday afternoon was given in Campbell Hall; the joint session on Friday morning with Section E was held in Mendenhall Hall; all other sessions were held in the Horticulture and Forestry Building of the Ohio State University.

Arrangements for the meetings were made by a committee consisting of Professors S. E. Rasor (Chairman), Lincoln LaPaz, J. H. Weaver, and F. B. Wiley. The dormitory and social rooms of Neil Hall were made available for the use of the visiting mathematicians.

Over four hundred persons registered including the following two hundred eighty-six members of the Society, the largest attendance at an annual meeting in the history of the Society:

V. W. Adkisson, R. P. Agnew, Leonidas Alaoglu, A. A. Albert, G. E. Albert, H. W. Alexander, C. B. Allendoerfer, W. E. Anderson, Emil Artin, Max Astrachan, J. V. Atanasoff, C. S. Atchison, H. T. R. Aude, Frank Ayres, W. L. Ayres, R. W. Babcock, F. R. Bamforth, G. M. Bareis, I. A. Barnett, R. C. F. Bartels, E. F. Beckenbach, E. R. Beckwith, M. M. Beenken, A. A. Bennett, S. F. Bibb, G. D. Birkhoff, H. L. Black, Archie Blake, Henry Blumberg, L. M. Blumenthal, R. P. Boas, Salomon Bochner, Paul Boeder, D. G. Bourgin, J. W. Bower, M. G. Boyce, J. W. Bradshaw, J. B. Brandeberry, A. T. Brauer, W. C. Brenke, F. L. Brooks, O. E. Brown, G. S. Bruton, C. T. Bumer, R. S. Burington, Jewell H. Bushey, W. E. Byrne, W. D. Cairns, J. W. Calkin, H. H. Campaigne, H. C. Carter, W. B. Carver, E. W. Chittenden, R. V. Churchill, E. H. Clarke, W. W. S. Claytor, R. F. Clippinger, L. M. Coffin, L. W. Cohen, J. B. Coleman, A. H. Copeland, W. A. Cordrey, A. P. Cowgill, L. C. Cox, M. M. Culver, H. B. Curtis, J. H. Curtiss, A. H. Diamond, R. P. Dilworth, L. L. Dines, H. A. DoBell, J. L. Doob, H. H. Downing, W. C. Doyle, Arnold Dresden, R. J. Duffin, P. S. Dwyer, J. J. Eachus, E. D.:Eaves, Samuel Eilenberg, W. H. Erskine, G. C. Evans, G. W. Evans, H. P. Evans, F. A. Ficken, B. F. Finkel, F. A. Foraker, L. R. Ford, W. B. Ford, Orrin Frink, T. C. Fry, D. G. Fulton, A. S. Galbraith, M. C. Garvin, B. E. Gatewood, H. M. Gehman, Abe Gelbart, F. J, Gerst, Lachlan Gilchrist, Wallace Givens, L. M. Graves, J. W. Green, V. G. Grove. 
D. W. Hall, N. A. Hall, P. R. Halmos, O. G. Harrold, M. C. Hartley, M. L. Hartung, G. G. Harvey, O. C. Hazlett, E. R. Hedrick, A. E. Heins, M. H. Heins, E. D. Hellinger, Fritz Herzog, M. R. Hestenes, H. C. Hicks, J. J. L. Hinrichsen, D. L. Holl, T. R. Hollcroft, P. M. Hummel, E. V. Huntington, W. A. Hurwitz, D. H. Hyers, Dunham Jackson, R. D. James, E. D. Jenkins, Walter Jennings, Fritz John, R. P. Johnson, F. E. Johnston, B. W. Jones, H. A. Jordan, Mark Kac, Samuel Kaplan, Wilfred Kaplan, L. C. Karpinski, Chosaburo Kato, D. K. Kazarinoff, J. L. Kelley, R. B. Kershner, J. R. Kline, L. A. Knowler, Alfred Korzybski, H. W. Kuhn, A. C. Ladner, W. D. Lambert, K. W. Lamson, O. E. Lancaster, H. G. Landau, R. E. Langer, H. L. Langhaar, Lincoln LaPaz, C. G. Latimer, C. E. Leach, Solomon Lefschetz, D. H. Lehmer, R. A. Leibler, J. H. Levin, Norman Levinson, G. H. Ling, Marie Litzinger, M. I. Logsdon, A. T. Lonseth, E. R. Lorch, C. I. Lubin, P. H. McGrath, C. C. MacDuffee, Saunders MacLane, H. M. MacNeille, M. M. Maloney, J. D. Mancill, Dorothy Manning, R. G. Mason, Karl Menger, A. N. Milgram, D. D. Miller, E. W. Miller, Virginia Modesitt, M. G. Moore, Max Morris, Richard Morris, R. C. Morrow, Marston Morse, E. J. Moulton, J. R. Musselman, F. C. Ogg, Rufus Oldenburger, E. G. Olds, E. J. Olson, E. R. Ott, J. R. Overman, W. V. Parker, E. W. Paxson, D. T. Perkins, O. J. Peterson, Everett Pitcher, V. C. Poor, G. B. Price, Tibor Radó, J. F. Randolph, S. E. Rasor, F. W. Reed, Eric Reissner, R. G. D. Richardson, C. E. Rickart, P. R. Rider, R. F. Rinehart, H. P. Robertson, W. H. Roever, J. B. Rosenbach, J. E. Rosenthal, Barkley Rosser, E. H. Rothe, N. E. Rutt, O. F. G. Schilling, I. J. Schoenberg, G. E. Schweigert, C. E. Sealander, Seymour Sherman, C. G. Shover, D. R. Shreve, D. T. Sigley, M. E. Sinclair, E. R. Sleight, M. M. Slotnick, M. F. Smiley, E. R. Smith, F. C. Smith, J. P. Smith, T. L. Smith, W. F. Smith, Virgil Snyder, D. C. Spencer, G. W. Starcher, N. E. Steenrod, H. E. Stelson, C. N. Stokes, R. W. Stokes, E. C. Stopher, W. T. Stratton, E. C. Strayhorn, Otto Szász, J. S. Taylor, M. E. Taylor, W. C. Taylor, H. P. Thielman, J. M. Thomas, R. M. Thrall, E. W. Titt, C. C. Torrance, H. C. Trimble, W. J. Trjitzinsky, P. L. Trump, A. W. Tucker, F. W. Urban, J. L. Vanderslice, J. H. Van Vleck, J. I. Vass, R. W. Wagner, G. W. Walker, A. D. Wallace, J. L. Walsh, S. E. Warschawski, J. H. Weaver, Warren Weaver, M. S. Webster, M. J. Weiss, C. P. Wells, M E. Wescott, G. T. Whyburn, Norbert Wiener, L. R. Wilcox, R. L. Wilder, F. B. Wiley, C. W. Williams, K. P. Williams, E. W. Wilson, Aurel Wintner, F. L. Wren, C. R. Wylie, M. M. Young, J. W. T. Youngs, R. T. Zoch, Max Zorn.

The meeting opened at 2:00 Tuesday afternoon with sections for Analysis and for Topology. Professors L. L. Dines and G. T. Whyburn presided at these two sessions.

Provost E. R. Hedrick presided at the general session on Wednesday morning. On Wednesday afternoon there were three sessions, for Analysis, for Algebra, and for Logic and the Theory of Sets. Professors M. R. Hestenes, C. C. MacDuffee, and L. M. Blumenthal presided. On Thursday afternoon there were sessions for Applications and for Topology, at which Professors Norbert Wiener and Solomon Lefschetz presided. On Friday morning Professor Arnold Dresden presided at the section for Analysis.

On Wednesday afternoon Professor Theodore von Kármán, 
Director of the Guggenheim Aeronautical Laboratory of the California Institute of Technology, delivered the fifteenth Josiah Willard Gibbs Lecture before a joint session of the Society and the American Association for the Advancement of Science. His subject was The engineer grappling with non-linear problems. Professor G. C. Evans, President of the Society, presided at this lecture.

The opening session of the American Association for the Advancement of Science was held on Wednesday evening at which Dr. W. C. Mitchell delivered the retiring presidential address on The public relations of science. This was followed by a reception for all members of the A.A.A.S. and affiliated societies at the Deshler-Wallick Hotel.

The general session on Wednesday morning opened with the business meeting and annual election. At this time the Frank Nelson Cole Prize in Algebra was awarded to Professor A. A. Albert for his papers On the construction of Riemann matrices, published in the Annals of Mathematics, vol. 35 (1934), pp. 1-28; vol. 36 (1935), pp. 376-394. This was followed by a joint session of the Society, the Association and Section A of the A.A.A.S. at which Professor J. R. Kline, as retiring Vice President of the A.A.A.S. and Chairman of Section A, gave an address entitled The Jordan curve theorem. The President of the Society, Professor G. C. Evans, presided.

At the general session on Thursday afternoon, by invitation of the Committee on Invited Speakers, Professor D. H. Lehmer delivered an address on The application of Bernoulli polynomials to some problems in Diophantine analysis. Professor H. W. Kuhn presided at this lecture.

On Friday morning the section for Applied Mathematics met jointly with the Association and Sections $A$ and $E$ of the A.A.A.S. At this session the following five addresses were given: The beginnings of mathematical geophysics in Great Britain by W. D. Lambert, Use of mathematics in the delineation of magnetic and electric anomalies by Professor Lachlan Gilchrist, Gravimetric and seismic methods in exploratory geophysics by Dr. M. M. Slotnick, Mathematical problems in seismology by Dr. Archie Blake, Some seismological problems by Professor Perry Byerly. In the absence of Professor Byerly, his prepared address was read by Professor W. D. Cairns. Professor Marston Morse, Chairman of Section A, presided at this joint session.

Sessions of the Mathematical Association were held on Friday afternoon and Saturday morning, and sessions of the National Council of Teachers on Friday morning and afternoon.

A joint dinner for the mathematical organizations and their guests 
was held at the Faculty Club on Thursday evening. The attendance was two hundred eighty-three. Professor Tibor Radó was toastmaster and introduced Dean B. L. Stradley who welcomed the visitors to Columbus and the Ohio State University. Professor H. C. Christofferson called attention to some interesting trends in enrollments of grade school, secondary and college students in the past fifty years. Professor R. E. Langer discussed some proposed policies of the Association. Professor G. D. Birkhoff spoke of the origin and workings of the Putnam Prize Competition. Professor J. M. Thomas pointed to the vigorous but alarming growth in published research in this country and proposed that authors "Write less better." At the close of the dinner Dean G. H. Ling presented resolutions, which were adopted unanimously, expressing the appreciation of the mathematical groups to the Ohio State University and the local committee for the excellent arrangements and generous hospitality.

The ladies of the local Department of Mathematics served tea in Neil Hall on Tuesday and Friday afternoons for visiting mathematicians and guests. There was also a tea at the Governor's Mansion on Thursday afternoon.

At the meeting of the Board of Trustees at 7:30 P.M., Tuesday, December 26, in a social room of Neil Hall, there was not a quorum present. An adjourned meeting, therefore, was held on January 1, at 12:30 P.M., in the Men's Faculty Club of Columbia University, New York City.

The Council met on Wednesday, December 27, at 7:30 P.M. in a social room of Neil Hall. An adjourned meeting was held on Thursday at $11: 15$ P.M.

The Secretary announced the election of the following twentyeight persons to membership in the Society:

Sister Anastasia Maria, Immaculata College, Immaculata, Pa.;

Miss Lois E. Bell, Independence Junior College, Independence, Kan.;

Mr. Kenneth Arthur Bush, Bard College, Annandale-on-Hudson, N.Y.;

Miss Mary Louise Constable, Philadelphia High School for Girls;

Mr. Commodore Columbus Dearman, Jr., East Central Junior College, Decatur, Miss.;

Mr. Bernard Dimsdale, University of Idaho;

Professor Solomon Dobrin, Jr., Essex Junior College, Newark, N.J.;

Mr. William Holt Glenn, Jr., Pasadena Junior College;

Dr. Michael Golomb, School of Electrical Engineering, Cornell University;

Professor Alberto Gonzalez Dominguez, Brown University;

Dr. Albert Edward Heins, Purdue University;

Dr. Stephen Arthur Jennings, Yale University;

Professor Pete Singleton Leach, Middle Georgia College, Cochran, Ga.;

Mr. Joseph Harmon Levin, Wayne University; 
Mr. Hunter John McConnell, Salt Lake City, Utah;

Reverend Philip H. McGrath, St. Peter's College, Jersey City, N.J.;

Mr. Thomas Henry Murtaugh, Fordham University;

Dr. Andrewa R. Noble, Berkeley, Calif.;

Dr. Eric Reissner, Massachusetts Institute of Technology;

Mr. W. Murray Robertson, Pennsylvania Railroad, Narberth, Pa.;

Dr. Louis D. Rodabaugh, University of Alabama;

Dr. Peter Scherk, Taft School, Watertown, Conn.;

Mr. Morris Herbert Shamos, New York, N.Y.;

Professor Herman Walton Smith, Oklahoma Agricultural and Mechanical College;

Dr. Chester Snow, National Bureau of Standards, Washington, D.C.;

Dr. Donald Clayton Spencer, Massachusetts Institute of Technology;

Dr. Charles P. Wells, Michigan State College;

Mr. Max Wyman, California Institute of Technology.

It was reported that the following had been elected as nominees on the Institutional Memberships of the institutions indicated:

Bowdoin College: Mr. Dan Edwin Christie (at Princeton University).

Brooklyn College: Mrs. Mary I. Draper Boeker.

Brown University: Dr. Willy K. Feller, Messrs. George Elmer Forsythe, John George Herriot, Joseph Albert Joseph, and Olaf Schmidt.

Bryn Mawr College: Dr. Hilda Geiringer and Miss Dorothy Maharam.

University of California: Mr. Douglas George Chapman and Miss Orla Virginia Wood.

University of California at Los Angeles: Messrs. Jule Gregory Charney and Harry Lass.

University of Chicago: Miss Katherine Elizabeth Hazard, Messrs. William Karush and Herman Lewis Meyer, Jr.

College of the City of New York: Mr. Kenneth J. Arrow.

Columbia University: Messrs. Seymour Jablon, Robert Alex McKean, Don Mittleman, and Fred Supnick.

Cornell University: Professor Walter Rue Murray (Franklin and Marshall College) and Mr. Edward Oscar Stephany.

Harvard University: Messrs. Maurice Haskell Heins and Edwin Norman Nilson, and Hon. John Lord O'Brien (of Buffalo, N.Y.).

University of Illinois: Messrs. David Harold Blackwell, Abraham Charnes, Robert W. Gibson, Nathan Goldman, and Yudell Leo Luke.

Indiana University: Mr. David Gilbarg and Miss Margaret Ellen Stump.

Institute for Advanced Study: Drs. Alfred Theodor Brauer and Clifford Hugh Dowker, Professor Guido Fubini, Mr. Albert Edward Ingham (King's College, Cambridge, England), and Professor Charles Eugene Springer (University of Oklahoma).

The State University of Iowa: Mr. Carl Elroy Noble.

Iowa State College: Mr. Roy Herbert Cook.

The Johns Hopkins University: Mr. Samuel G. Bourne, Miss Florence Jessie Collinson, Mr. Alfred Levine, Miss Yael Naim, and Mr. Harold Kenneth Sohl.

University of Kentucky: Mr. William Glenn Clark.

Lehigh University: Mr. Eugene Park.

Massachusetts Institute of Technology: Messrs. Francis Begnaud Hildebrand, Carl Gustaf Allan Nordling, and Claude E. Shannon. 
University of Michigan: Dr. Samuel Eilenberg and Mr. Sheng Chin Fan.

University of Minnesota: Miss Margaret Pearl Martin, Messrs. William Robert McEwen and Frank Joseph Polansky.

Northwestern University: Messrs. Theodore Wilbur Anderson, Jr., Harold Elra Burns (Indiana University Extension, East Chicago, Ind.), Thomas Elias Caywood, Edwin Leonidas Godfrey (Indiana University Extension, East Chicago, Ind.), and Ralph Eldon Lane (Flitcraft, Inc., Oak Park, Ill.).

University of Pennsylvania: Mr. Hyman N. Laden.

University of Rochester: Mr. Henry Pearce Atkins.

The College of St. Thomas: Mr. George Joseph Haltiner (of St. Paul).

Stanford University: Messrs. Charles Lester Clark and Stanley Eugene Rauch.

Syracuse University: Mr. Barnard Hinkle Bissinger.

University of Virginia: Mr. Franklin Guy Myers.

University of Washington: Misses Kathryn Eleanor Benson and Mary Elizabeth Layne.

Wellesley College: Professor Harriet Whitney Allen (Hollins College, Hollins, Va.). University of Wisconsin: Messrs. Burton Houston Colvin, Wilhelm S. Erickson, William Grenfell Leavitt, and Clarence Bernhart Lindquist.

The University of Minnesota was elected to Institutional Contributing Membership in the Society.

Professor Francesco Tricomi of the University of Turin was admitted to the Society in accordance with the reciprocity agreement with the Unione Matematica Italiana.

The following appointments by President G. C. Evans were reported: as representative of the Society at the inauguration of Frank Jay Prout as President of Bowling Green State University on October 21, Professor J. B. Brandeberry; as representative of the Society at the inauguration of John Benjamin Magee as President of Cornell College on October 27, Professor E. W. Chittenden; as representatives of the Society at the Centenary Celebration of the American Statistical Association in Boston on November 27, Professor G. D. Birkhoff, and in Philadelphia on December 29, Professor S. S. Wilks; as representative of the Society at the inauguration of Homer Price Rainey as President of the University of Texas on December 9, Professor R. L. Moore; as a Committee on Arrangements for the 1940 Spring Meeting in Washington, D.C., Professor F. E. Johnston (chairman), Dr. Archie Blake, Professors T. R. Hollcroft, A. E. Landry, Florence M. Mears, E. W. Titt, and F. M. Weida; as a Committee on Arrangements for the Summer Meeting of 1940, Professors F. W. Perkins (chairman), W. D. Cairns, T. R. Hollcroft, Robin Robinson, L. L. Silverman, and H. L. Slobin; as a Committee on Arrangements for the Annual Meeting of 1940, Professors S. T. Sanders (chairman), W. L. Ayres, H. E. Buchanan, W. D. Cairns, W. V. Parker, and N. E. Rutt; as additional members of the Com- 
mittee on Publicity, Mr. R. M. Foster and Dr. J. M. Thompson; as tellers for the election at the 1939 Annual Meeting, Professor F. R. Bamforth and Dr. E. R. Lorch; as auditors of the Society's books for the year 1939, Professors R. G. Archibald and A. E. Meder, Jr.; as the Committee on Nomination of Officers and Members of the Council for 1941, Professors Arnold Dresden (chairman), L. M. Graves, E. R. Hedrick, R. L. Moore, and J. L. Walsh.

The following representatives of the Society were appointed: on the Editorial Board of the Annals of Mathematics for a period of three years beginning with 1940, Professors T. H. Hildebrandt, Saunders MacLane, and G. T. Whyburn; on the Division of Physical Sciences of the National Research Council for a period of three years beginning July 1, 1940, Professor G. C. Evans; on the Council of the American Association for the Advancement of Science for the year 1940, Professors Arnold Dresden and J. R. Kline; on the advisory board of The Kosciuszko Foundation to assist Polish scholars, Professor J. R. Kline.

The Secretary reported that the ordinary membership in the Society is now 2,283, including 200 nominees of institutional members and 79 life members. There are also 87 institutional members. The total attendance of members at all meetings in 1939 was 1,354 ; the number of papers read was 489 ; the number of invited addresses was 10 ; the number of members attending at least one meeting was 841 .

At the annual election which closed on December 27, and at which 406 votes were cast (no person not on the ballot receiving more than one vote for any office) (375 for the list nominated by the Council), the following officers were elected:

Vice Presidents, Dr. T. C. Fry and Professor F. D. Murnaghan. Secretary, Dean R. G. D. Richardson.

Associate Secretaries, Professors W. L. Ayres and M. H. Ingraham, and Dean T. M. Putnam.

Member of the Editorial Committee of the Bulletin, Professor P. A. Smith.

Member of the Editorial Committee of the Transactions, Professor C. C. MacDuffee.

Member of the Editorial Committee of the Colloquium Publications, Professor J. D. Tamarkin.

Members of the Council, Professors L. E. Dickson, C. G. Latimer, N. H. McCoy, Saunders MacLane, and W. M. Whyburn.

The Secretary requested that the Society accept his resignation to take effect not later than the end of 1940. 
The reports of the Treasurer and auditors (Professors R. G. Archibald and A. E. Meder, Jr.) showed a balance of $\$ 9,405.61$ exclusive of the balances in the Colloquium, Sinking Fund, and special funds. The Society's investments including Endowment Fund, Sinking Fund, and other special funds had a market value on November 30 , 1939 , of approximately $\$ 150,000.00$. The net interest income for the year was $\$ 5,377.25$; dues from Institutional Memberships amounted to $\$ 6,530.00$; dues from Contributing Memberships, $\$ 1,163.92$; and dues from Ordinary Memberships were $\$ 13,541.71$. The Colloquium Fund showed a balance of $\$ 8,075.38$. The total received from the sale of the Society's publications was $\$ 11,534.24$. The Board of Trustees adopted a budget for 1940 showing estimated expenditures and receipts of the Society (including Mathematical Reviews) as $\$ 53,800.00$ and $\$ 40,800.00$ respectively.

The Librarian reported that the Library of the Society now contains about 9,475 volumes.

The American Journal of Mathematics, which is published jointly by the Johns Hopkins University and the Society and to which the Society gives an annual subvention of $\$ 2,500$, printed 1,008 pages during 1939.

An invitation from Dartmouth College to hold the 1940 Summer Meeting in Hanover, New Hampshire, was accepted, and the meeting was set for September 10-12. On invitation, the 1941 Summer Meeting is to be held at the University of Chicago in connection with its Semicentennial Celebration. There will be a meeting of the Society at Seattle, Washington, in June 1940, in affiliation with the American Association for the Advancement of Science. Times and places of additional meetings during 1940 were set as follows: February 24 and October 26 in New York, April 6 in Berkeley, December 30, 1940-January 1, 1941 in Baton Rouge.

On recommendation of the Committee on Special Membership Rates, the following addition to Article VI of the by-laws was recommended to the Society:

Section 9. Any member who has been retired from active service on account of age and has been a member of the Society for twenty years or more may, upon notification to the Secretary of such retirement, have his dues remitted, on the understanding that he will thereafter receive the programs of the meetings, but not the Bulletin.

This change in the by-laws will be submitted to the Society for vote at the meeting on February 24, 1940.

A proposal from the Committee on the Disposition of Interest on Special Funds is to lie over for consideration until the next meeting 
of the Council. This proposal involves the inauguration by the Society of a new series of books, somewhat smaller in size than books of the Colloquium Series and devoted chiefly to exposition of advanced topics.

Copies of the first number of Mathematical Reviews were on exhibition at the meeting. Eight hundred subscribers are already on the books. Three hundred fifty mathematicians, in all parts of the world, have accepted invitations to be reviewers. Arrangements are being made with various organizations for joint sponsorship of the journal with the Society.

A grant of one thousand dollars was announced from the Rockefeller Foundation for an experimental period of two years for the filming of all mathematical papers reviewed in the Mathematical Reviews.

The Emergency Executive Committee of the International Congress of Mathematicians which was to have been held in Cambridge, Massachusetts, in September 1940, announced that on December 20, 1939, notice was sent to all persons interested that the Congress has been postponed.

It was decided that no Josiah Willard Gibbs Lecture would be given during the year 1940 .

Professor R. L. Wilder was invited to give the Colloquium Lectures in 1942. It was announced that Professor G. T. Whyburn had been asked to give his Colloquium Lectures in 1940. A book entitled Lattice Theory by Professor Garrett Birkhoff was accepted for publication in the Colloquium Series.

The Transactions editors announced that space is now available promptly in that journal. Professor E. T. Bell's term having expired, Professor Saunders MacLane has been appointed associate editor in his place.

Professor M. H. Stone proposed that a letter be sent to sister mathematical organizations in various parts of the world, suggesting that mathematicians use their influence to conserve the scientific resources of the world against the day when peace shall reign once more and to mitigate in every way possible the horrors of war. This proposal is to be presented to the Society for its action at the February meeting.

Titles and cross references to the abstracts of papers read at the sessions follow below. The papers were read as follows: papers numbered 1 to 6 in the section for Analysis on Tuesday afternoon; papers 7 to 12 in the section for Topology on Tuesday afternoon; papers 13 to 20 in the general session on Wednesday morning; papers 21 to 28 
in the section for Analysis on Wednesday afternoon; papers 29 to 35 in the section for Algebra on Wednesday afternoon; papers 36 to 40 in the section for Logic and the Theory of Sets on Wednesday afternoon; papers 41 to 49 in the section for Applications on Thursday afternoon; papers 50 to 55 in the section for Topology on Thursday afternoon; papers 56 to 62 in the section for Analysis on Friday morning; and papers 63 to 102, whose abstract numbers are foll owed by the letter $t$, were read by title. Professor H. W. Smith was introduced by Professor O. H. Hamilton, Dr. Stefan Bergman by Professor W. T. Martin, Dr. M. H. Heins by Professor J. L. Walsh, Dr. D. C. Spencer and Dr. Samuel Eilenberg by Professor W. L. Ayres, Dr. A. T. Brauer by Professor Hermann Weyl, Dr. Alexander Wundheiler by Professor D. J. Struik, Professor André Gleyzal and Dr. M. S. Hendrickson by Professor Henry Blumberg, Dr. A. E. Heins by Professor A. H. Smith, and Dr. W. A. Patterson by Professor Lincoln LaPaz. Paper 4 was presented by Dr. J. J. Eachus, paper 8 by Dr. P. V. Reichelderfer, paper 12 by Professor E. W. Miller, paper 28 by Professor Marston Morse, paper 42 by Dr. Eric Reissner, paper 48 by Professor Norbert Wiener, and paper 55 by Dr. D. W. Hall.

1. Mark Kac: On the partial sums of the exponential series. (Abstract 46-1-90.)

2. Norman Levinson: $A$ proof of Hardy's theorem on the zeros of the zeta function. (Abstract 46-1-96.)

3. D. G. Bourgin: The Dirichlet problem for the damped wave equation. (Abstract 46-1-49.)

4. R. J. Duffin and J. J. Eachus: Sets invariant under a polynomial operator. (Abstract 46-1-63.)

5. Otto Szász: On strong summability of Fourier series. (Abstract 46-1-127.)

6. Alfred Korzybski: General semantics: extensionalization in mathematics, mathematical physics, and general education. III. Over/ under defined terms. (Abstract 45-11-424.)

7. A. D. Wallace: Relatively non-alternating transformations. (Abstract 46-1-131.)

8. Tibor Radó and P. V. Reichelderfer: On cyclic transitivity. (Abstract 46-1-30.)

9. J. W. T. Youngs: $A$ remark on cyclic transitivity. (Abstract 46-1-136.)

10. O. G. Harrold (National Research Fellow): Exactly $(k, 1)$ transformations on linear graphs. (Abstract 46-1-76.) 
11. G. E. Schweigert: $A$ local property arising from certain interior transformations. (Abstract 46-1-120.)

12. Samuel Eilenberg and E. W. Miller: On 0-dimensional uppersemi-continuous collections. (Abstract 46-1-67.)

13. R. D. James: $A$ problem analogous to the problem of prime pairs. (Abstract 46-1-85.)

14. A. A. Albert: On p-adic fields and cyclic algebras. (Abstract 46-1-44.)

15. W. J. Trjitzinsky: Some problems in the theory of singular integral equations. (Abstract 45-11-438.)

16. G. B. Price: On the theory of integration. (Abstract 46-1-114.)

17. I. J. Schoenberg: On metric arcs of vanishing Menger curvature. (Abstract 46-1-119.)

18. R. P. Boas: Some uniqueness theorems for entire functions. (Abstract 46-1-48.)

19. Karl Menger: On Cauchy's theorem in the real plane. (Abstract 46-1-104.)

20. Norbert Wiener: $A$ canonical series for symmetric functions in statistical mechanics. (Abstract 46-1-133.)

21. H. W. Smith: The oscillation of solutions of the differential boundary value problems of the fourth order. (Abstract 46-1-125.)

22. C. E. Sealander: Some third order irregular boundary value problems. (Abstract 46-1-122.)

23. Stefan Bergman: On the approximation of functions satisfying a linear partial differential equation. (Abstract 46-1-46.)

24. J. W. Calkin: Semi-bounded forms and self-adjoint boundary value problems. (Abstract 46-1-52.)

25. M. H. Heins: On the conformal mapping of a multiply-connected region into itself. (Abstract 46-1-78.)

26. D. C. Spencer: On mean one-valent functions. (Abstract 46-1-126.)

27. Abe Gelbart: On the growth of a function of two complex variables given by its power series expansion on certain hypersurfaces. (Abstract 46-1-71.)

28. Marston Morse and C. B. Tompkins: Minimal surfaces of unstable type. (Abstract 46-3-149.)

29. D. T. Sigley: $k$-set groups. (Abstract 45-11-436.)

30. B. W. Jones: Related genera of quadratic forms. Preliminary report. (Abstract 46-1-87.)

31. C. G. Latimer: On a certain equation. (Abstract 46-1-95.)

32. R. P. Dilworth: Ideals in Birkhoff lattices. (Abstract 46-1-61.) 
33. Max Zorn: Alternative rings with nilpotent elements. (Abstract 46-1-137.)

34. A. T. Brauer: On the density of the sum of sets of positive integers. II. (Abstract 46-1-50.)

35. R. F. Clippinger: On matrix products of positive powers of given matrices. Preliminary report. (Abstract 46-1-55.)

36. A. H. Diamond: Postulates for the theory of strict implication. (Abstract 46-1-60.)

37. Walter Jennings: Some implications of the continuum hypothesis. (Abstract 46-1-86.)

38. L. W. Cohen: On topological completeness. (Abstract 46-1-56.)

39. Seymour Sherman: Some new properties of transfinite ordinals. (Abstract 46-1-123.)

40. André Gleyzal: A general theorem on the structure of linear orders. (Abstract 46-1-73.)

41. A. E. Heins: The solution of the discrete wave equation. (Abstract 46-1-16.)

42. Eric Reissner and H. A. Wood: On boundary value problems of bi-potential theory for an infinite sector. (Abstract 46-1-115.)

43. Rufus Oldenburger: Symbolic elements in dynamics. (Abstract 46-1-111.)

44. A. H. Copeland: Transformations on probability sequences. (Abstract 46-1-57.)

45. J. L. Doob: On a certain type of family of chance variables. (Abstract 46-1-62.)

46. M. E. Wescott: Sets of Newton polynomials analogous to Laguerre's polynomials. (Abstract 46-1-132.)

47. Barkley Rosser: On the computation of logarithms to a large number of decimal places. (Abstract 46-1-117.)

48. Alexander Wundheiler: Are complex numbers vectors? (Abstract 46-1-135.)

49. H. W. Alexander: On the edge of regression of a general surface. (Abstract 46-1-45.)

50. J. L. Kelley: On the hyperspaces of a given space. Preliminary report. (Abstract 46-1-94.)

51. Samuel Eilenberg: An invariance theorem for subsets of $S^{n}$. (Abstract 46-1-64.)

52. R. L. Wilder:'Local connectedness and generalized manifolds. (Abstract 46-1-134.)

53. A. N. Milgram: Iterations of mappings of a set on its square. (Abstract 46-1-105.) 
54. A. W. Tucker: The algebraic structure of complexes. II. Preliminary report. (Abstract 46-1-128.)

55. D. W. Hall and G. T. Whyburn: On arc-preserving and tree preserving transformations. (Abstract 46-3-143.)

56. E. R. Lorch: Spectral analysis of weakly almost periodic transformations in reflexive vector spaces. (Abstract 45-11-401.)

57. M. S. Hendrickson: On certain properties of arbitrary functions. (Abstract 46-1-79.)

58. Dunham Jackson: Note on certain orthogonal polynomials. (Abstract 46-1-84.)

59. M. F. Smiley: $A$ note on the Jacobi condition for extremaloids. (Abstract 46-1-124.)

60. W. A. Patterson: Inverse problems of the calculus of variations for multiple integrals. (Abstract 46-1-112.)

61. J. D. Mancill: On the Carathéodory condition for unilateral variations. (Abstract 46-1-102.)

62. M. R. Hestenes: A theorem on quadratic forms and its application in the calculus of variations. (Abstract 46-1-83.)

63. H. L. Garabedian: Theorems associated with the Riesz and the Dirichlet's series methods of summation. (Abstract 45-11-417-t.)

64. A. D. Hestenes: $A$ solution of the nonhomogeneous $\phi$-difference equation of the first order. Preliminary report. (Abstract 46-1-81-t.)

65. R. G. Lubben : Separabilities of higher orders and related properties. (Abstract 46-1-99-t.)

66. F. B. Jones: Almost cyclic, elements and simple links of a continuous curve. (Abstract 46-1-88-t.)

67. H. A. Arnold: Postulates for the defective group. (Abstract 45-11-407-t.)

68. Mark Kac: On a problem concerning probability and its connection with the theory of diffusion. (Abstract 46-1-19-t.)

69. Garrett Birkhoff: An ergodic theorem for arbitrary semi-groups. (Abstract 46-1-9-t.)

70. W. T. Martin: Analytic functions and multiple Fourier integrals. (Abstract 46-1-23-t.)

71. F. J. Murray: Nullifying functions. (Abstract 46-1-26-t.)

72. Salomon Bochner: Finitely additive integral. (Abstract 46-110-t.)

73. R. P. Boas: A completeness theorem. (Abstract 46-1-47-t.)

74. R. S. Phillips: On linear transformations. (Abstract 46-1-113-t.)

75. O. G. Harrold (National Research Fellow): The dimensionality of continuous transforms of an n-cell. (Abstract 46-1-77-t.) 
76. O. G. Harrold (National Research Fellow): Continua of finite degree and certain product sets. (Abstract 46-1-75-t.)

77. H. F. MacNeish: A set of postulates for a finite geometry represented by the Pappus configuration. (Abstract 46-1-100-t.)

78. H. F. MacNeish: A sufficient condition for integrability. (Abstract 46-1-101-t.)

79. H. L. Garabedian: A new formula for the Bernoulli numbers. (Abstract 46-1-69-t.)

80. G. N. Garrison: Quasi-groups. (Abstract 46-1-70-t.)

81. Richard Brauer and H. S. M. Coxeter: A generalization of theorems of Schönhardt and Mehmke on polytopes. (Abstract 46-151-t.)

82. R. L. Moore: Concerning accessibility. (Abstract 46-1-108-t.)

83. R. L. Moore: Concerning domains whose boundaries are compact. (Abstract 46-1-109-t.)

84. F. B. Jones: Certain consequences of the Jordan curve theorem. (Abstract 46-1-89-t.)

85. W. T. Scott: Interpolation by continued fractions. (Abstract 46-1-121-t.)

86. F. A. Lewis: Generators of permutation groups simply isomorphic with $L F(2, p)$. (Abstract 46-1-97-t.)

87. I. M. Niven: Integers of quadratic fields as sums of squares. (Abstract 46-1-110-t.)

88. E. R. van Kampen: On uniformly almost periodic multiplicative and additive functions. (Abstract 46-1-91-t.)

89. J. D. Mancill: On the Jacobi condition for unilateral variations. (Abstract 46-1-103-t.)

90. Samuel Eilenberg: Fixed points for periodic transformations. (Abstract 46-1-65-t.)

91. Samuel Eilenberg: On the homotopy type of $S^{n}$. (Abstract 46-1-66-t.)

92. Benjamin Epstein: Growth properties of analytic functions of two complex variables. II. Preliminary report. (Abstract 46-1-68-t.)

93. Harriet M. Griffin:The abelian quasi-group. (Abstract 46-1-74-t.)

94. Leonard Carlitz: $A$ set of polynomials. (Abstract 46-1-53-t.)

95. Leonard Carlitz: On certain sums involving polynomials in a Galois field. (Abstract 46-1-54-t.)

96. L. I. Wade: Certain quantities transcendental over the field $\Phi(x)$, where $\Phi=G F\left(p^{n}\right)$. (Abstract 46-1-129-t.)

97. P. W. Gilbert: Two-to-one transformations on linear graphs. Preliminary report. (Abstract 46-1-72-t.) 
98. A. D. Hestenes: On the solutions of a certain functional equation $\phi_{c}(x)-c \log \phi_{c}(x)=x-c \log x+1$. Preliminary report. (Abstract 46-1-80-t.)

99. A. D. Hestenes: On certain matrix $\phi$-difference equations. Preliminary report. (Abstract 46-1-82-t.)

100. Deane Montgomery and Leo Zippin: A Hilbert axiom for topological transformation groups of space. (Abstract 46-1-107-t.)

101. W. C. Graustein: Harmonic minimal surfaces. (Abstract 46-3-142-t.)

102. E. D. Hellinger: Classes of monotone functions. Preliminary report. (Abstract 46-3-145-t.)

\author{
W. L. Ayres, \\ Associate Secretary
}

